J. Clin. Chem. Clin. Biochem.

Vol. 27,1989 , pp. $653-658$

(C) 1989 Walter de Gruyter \& Co.

Berlin - New York

\title{
Reasons for Intraindividual Inconstancy of the Digoxin Saliva to Serum Concentration Ratio
}

\author{
By $R$. Haeckel and H. M. Mühlenfeld \\ Institute for Laboratory Medicine, Zentralkrankenhaus St. Jürgenstraße, Bremen, F.R.G.
}

(Received March 17/June 27, 1989)

Summary: When a constant dose of digoxin was administered orally over several days, the digoxin concentration in saliva and erythrocytes rose faster than in serum. Thus, the saliva/serum concentration ratio was below 1.0 after a single dose and above 1.0 in the steady state.

The digoxin concentration was relatively high in "unstimulated" (more or less spontaneous) saliva and decreased with stimulation of the salivary flow rate. It therefore appeared that the actual salivary digoxin concentration depended on 2 components: the digoxin concentration in "stimulated" saliva depended only on the rapid diffusion from the blood into saliva, and the concentration in the "unstimulated" saliva depended on the rapid diffusion and on a slower exchange with the intracellular compartment. It is suggested that unstimulated saliva reflects the intracellular digoxin concentration and stimulated saliva reflects the free digoxin concentration of the serum.

Both effects must be taken in account when interpreting the saliva/serum ratio, and they may explain conflicting results in the literature.

\section{Introduction}

Saliva has been recommended for therapeutic drug monitoring because it is more convenient for sampling than blood $(1,2)$. Several authors have studied the use of saliva to measure the digoxin concentration and found a good or even excellent correlation between the concentrations in saliva and those in plasma or serum (tab. 1). Danhof \& Breimer (11), however, expressed doubts on the use of saliva for digoxin monitoring, in view of the substantial variation of the saliva/plassma ratio reported by Joubert et al. (12).

In the following we report on 2 phenomena which lead to intraindividual variability of the saliva/serum concentration ratio of digoxin. If they are completely understood they could provide additional useful information for the surveillance of patients on digoxin therapy.

\section{Materials and Methods}

\section{Materials}

Digoxin controls (cat. No. 9511-10) were purchased from Abbott Diagnostics (GmbH (D-6200 Wiesbaden), Therapeutic Drug Monitoring Control level 1 and 2 (cat. No. C 455-5) from Biorad (D-8000 München 50) and sodium metrizoate-Ficoll (Lymphoprep, cat. No. 350031, density 1.077) from Novo Industry Pharmazeutika (D-6500 Mainz).

\section{Methods}

Digoxin was determined with a TDx analyser (Abbott GmbH) following the manufacturer's instructions. The imprecision and recovery of the digoxin determination in control sera is reported in table 2. Furthermore 6 calibrators which are usually supplied with the reagent kit from Abbott were diluted $1+1$ with pool serum and saliva. Identical results were obtained, indicating that the same procedure could be used for both specimens.

The free fraction of digoxin was determined in ultrafiltrates which were obtained from venous blood with the centrifree ${ }^{\mathrm{TM}}$ micropartition system from Amicon GmbH (cat. No. 4104, D- 
5810 Witten). The ultrafilters were washed twice with distilled water and dried prior to use to improve the imprecision from filter to filter. The pH-value was adjusted in serum samples to 7.4 with $0.1 \mathrm{~mol} / 1 \mathrm{HCl}$. The centrifugation was performed at $1000 \mathrm{~g}$ for 20 minutes at $37^{\circ} \mathrm{C}$.

Saliva samples (13) were obtained with salivettes (W. Sarstedt, D-5223 Nümbrecht, catalogue No. 51.1534.001). Unstimulated saliva was obtained by placing the cotton roll of a salivette into the buccal or sublingual cavity, and left in this position for 4 minutes to become sufficiently soaked with saliva. Sufficient stimulated saliva was obtained by chewing on the cotton roll for about 30 seconds. When this sampling procedure was repeated several times, a break of 15 seconds was included between each roll.

The concentration of digoxin in erythrocytes was determined according to Gorodischer et al. (4) with some modifications: 20 $\mathrm{ml}$ heparinised venous blood were diluted with $20 \mathrm{ml} 0.85 \mathrm{~g} / 1$ $\mathrm{NaCl}$ and then passed through a Lymphoprep solution (30 min, $\left.1800 \min ^{-1}, 20^{\circ} \mathrm{C}\right)$. The supernatant was decanted and the pellet (after counting the number of erythrocytes) frozen for at least 2 hours. The thawed concentrate was subjected to ultra-

Tab. 1. Saliva/serum concentration ratios of digoxin reported in the literature.

\begin{tabular}{|c|c|c|c|}
\hline $\begin{array}{l}\text { Mean } \\
\text { saliva/serum } \\
\text { ratio }\end{array}$ & $\therefore$ Number of probands & $\begin{array}{l}\text { Correlation } \\
\text { coefficient }\end{array}$ & $\begin{array}{l}\text { Refer- } \\
\text { ence }\end{array}$ \\
\hline $1.14 \pm 0.48$ & $\begin{array}{l}34 \text { patients, } \\
\text { steady-state }\end{array}$ & 0.97 & 3 \\
\hline $0.78 \pm 0.07$ & $\begin{array}{l}18 \text { patients, } \\
\text { steady state }\end{array}$ & 0.99 & 4 \\
\hline $1.34 \pm 0.44$ & $\begin{array}{l}4 \text { healthy persons, } \\
\text { steady-state }\end{array}$ & $\left.0.63-0.88^{a}\right)$ & 5 \\
\hline $\left.1.68^{b}\right)$ & $\begin{array}{l}20 \text { patients, } \\
\text { steady-state }\end{array}$ & 0.90 & 6 \\
\hline 0.62 & $\begin{array}{l}14 \text { patients, } \\
\text { single dose }\end{array}$ & 0.58 & 7 \\
\hline $0.66 \pm 0.20$ & $\begin{array}{l}12 \text { patients, } \\
\text { steady-state }\end{array}$ & 0.71 & 8 \\
\hline $0.67 \pm 0.10$ & $\begin{array}{l}50 \text { patients, } \\
\text { steady-state }\end{array}$ & 0.96 & 9 \\
\hline $1.25 \pm 0.41$ & $\begin{array}{l}12 \text { healthy persons, } \\
\text { single dose }\end{array}$ & 0.90 & 10 \\
\hline
\end{tabular}

a) Correlation coefficients for individual subjects

b) Plasma concentration sonic treatment twice for 15 minutes at room temperature, with mixing between the 2 time periods. The haemolysate was now diluted $1+1$ with distilled water and centrifuged (30 min, $10000 \mathrm{~g}$ ). The supernatant was used for digoxin analysis $\left(c_{\mathrm{H}}\right)$. The digoxin concentration of single erythrocytes was calculated from the digoxin concentration of the diluted haemolysate $c_{\mathrm{H}}$ $\left(\mu \mathrm{g} \cdot 1^{-1}\right)$ :

$$
c_{\mathrm{E}}=\frac{2 c_{\mathrm{H}}}{\mathrm{E} \cdot \mathrm{V}_{\mathrm{E}}}
$$

$$
\text { is }
$$

$V_{E}$ represents volume of the single erythrocyte (fl) and $E$ the number of erythrocytes per litre of blood concentrate.

Alternatively, digoxin was determined in the blood cell compartment. The Lymphoprep and freezing steps were then omitted from the procedere described above. The digoxin concentration $c_{B C}$ was calculated according to Vermeij (15):

$$
c_{\mathrm{BC}}=\frac{c_{\mathrm{B}}-c_{\mathrm{P}}(1-\mathrm{HK})}{\mathrm{HK}}
$$

$c_{B}$ and $c_{P}$ represent the digoxin concentration in venous blood and plasma, respectively, and $\mathrm{HK}$ is the haematocrit fraction $(100 \%=1.0)$. The digoxin concentrations in the blood cell compartment were slightly higher than those in single erythrocytes. However, both values correlated well with each other (fig. 1). Therefore, in the following only results from the first procedure are reported.

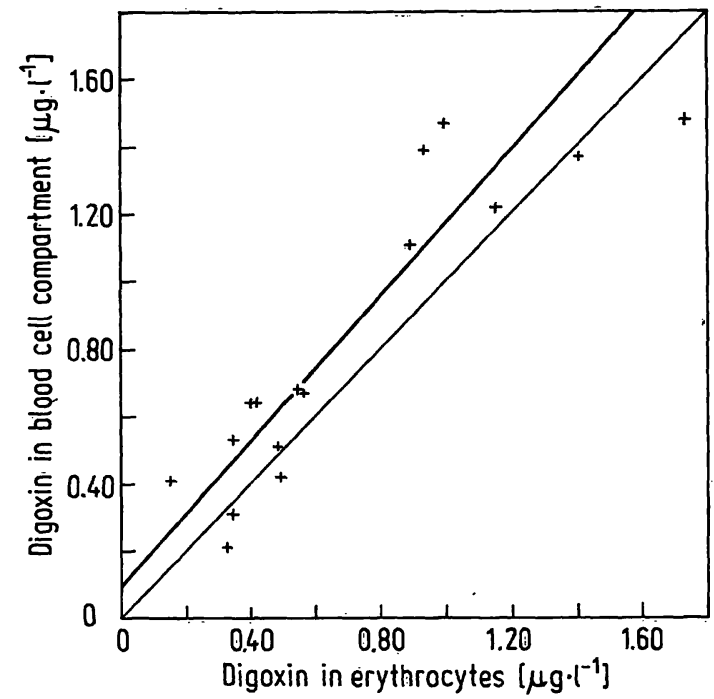

Fig. 1. The digoxin concentration in erythrocytes (calculated according to Gorodischer et al. (14)) and in the blood cell compartment (calculated according to Vermeij (15)). Standardised principal component analysis: $y=1.04 x$

\begin{tabular}{|c|c|c|c|c|c|c|}
\hline Material & $\begin{array}{l}\text { Assigned } \\
\text { value } \\
(\mu \mathrm{g} / \mathrm{l})\end{array}$ & Range & $\begin{array}{l}\text { Mean } \\
\text { value } \\
(\mu g / l)\end{array}$ & $\begin{array}{l}\text { Standard } \\
\text { deviation } \\
(\mu \mathrm{g} / \mathrm{l})\end{array}$ & $\begin{array}{l}\text { CV } \\
(\%) .\end{array}$ & $\mathbf{n}$ \\
\hline \multicolumn{7}{|l|}{ Imprecision within series } \\
\hline $\begin{aligned} & \text { Digoxin controls, } \text { low } \\
& \text { middle } \\
& \text { high }\end{aligned}$ & $\begin{array}{l}0.75 \\
1.50 \\
3.50\end{array}$ & $\begin{array}{l}0.55-0.95 \\
1.30-1.70 \\
3.15-3.85\end{array}$ & $\begin{array}{l}0.68 \\
1.47 \\
3.56\end{array}$ & $\begin{array}{l}0.06 \\
0.07 \\
0.13\end{array}$ & $\begin{array}{l}8.8 \\
4.7 \\
3.6\end{array}$ & $\begin{array}{l}10 \\
10 \\
10\end{array}$ \\
\hline Between-days imprecision & & & & & & \\
\hline $\begin{array}{l}\text { Digoxin control, middle } \\
\text { Therapeutic drug } \\
\text { monitoring control }\end{array}$ & 1.50 & $1.30-1.70$ & 1.49 & 0.07 & 4.7 & 30 \\
\hline $\begin{array}{l}\text { Level } 1 \\
\text { Level } 2\end{array}$ & $\begin{array}{l}0.71 \\
1.72\end{array}$ & $\begin{array}{l}0.57-0.85 \\
1.37-2.19\end{array}$ & $\begin{array}{l}0.71 \\
1.45\end{array}$ & $\begin{array}{l}0.07 \\
0.09\end{array}$ & $\begin{array}{l}9.8 \\
6.2\end{array}$ & $\begin{array}{l}30 \\
30\end{array}$ \\
\hline
\end{tabular}
$+0.10(n=17)$; coefficient of correlation $r=0.86$.

Tab. 2. Imprecision of the digoxin determination with a TDx analytical system. 
Digoxin (Lanicor ${ }^{\circledR}$ tablets from Boehringer Mannheim Corp.) was administered orally to 6 men (23-50 years) and one women (48 years), who were not aware of any disease and followed their usual professional lives.

Fitting lines were calculated by standardised principle component analysis (16). The study was accepted by the local commission on medical ethics.

\section{Results}

The use of salivettes means that saliva sampling was standardised to some extent (13). With appropriate sampling times (between 15 seconds and several minutes) the salivary flow rate can be estimated from the saliva taken up by the dental cotton roll of the salivette during a defined time. Using this technique it was found that the salivary flow rate increased more than fourfold after stimulation by chewing. In figure 2 , a representative example is shown which had been repeated 5 times. The sublingual flow rate was always higher than the buccal flow rate. This particular finding was not observed in 3 other probands.
The digoxin concentration was highest in unstimulated saliva, it declined with continuation of the saliva flow and reached a plateau level after a few minutes. When the stimulation by chewing was interrupted, the digoxin concentration rose again (fig. 2). Therefore, the digoxin concentration in unstimulated saliva appears to have 2 components: one is independent of the flow rate and is readily transferred into saliva (plateau level); the other depends on the flow rate, is much slower and is exhausted very soon after the flow rate is stimulated. Because of this effect, the saliva/ serum concentration ratio $\left(c_{\mathrm{SA}} / c_{\mathrm{S}}\right)$ differs for unstimulated and stimulated saliva.

The total digoxin concentration in serum was close to the concentration in unstimulated saliva, whereas the free serum concentration was only slighlty higher than the "plateau level" in stimulated saliva.

The salivary osmolality was surprisingly constant during the whole experiment, although slight fluctuations in unstimulated saliva were always observed in close parallelism with the digoxin and sodium concentra-

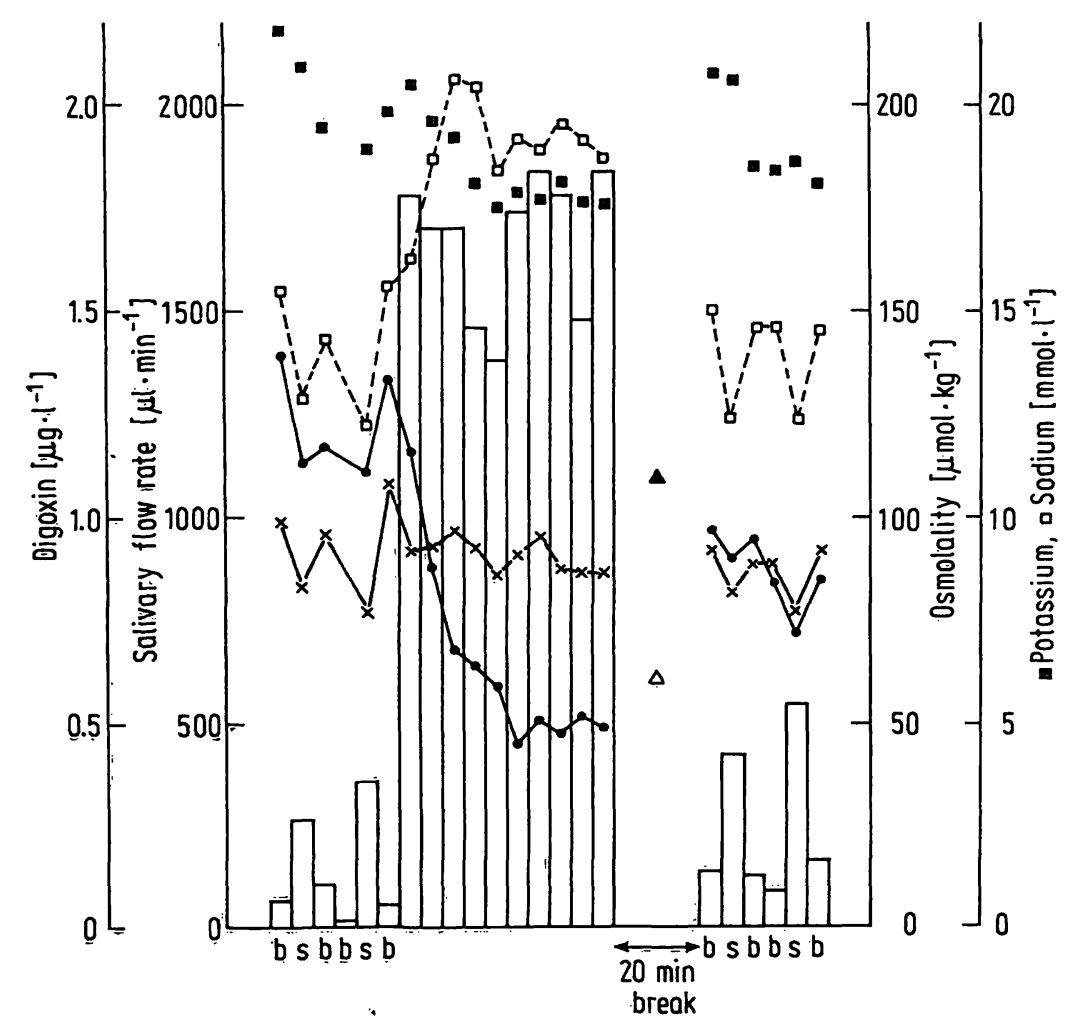

Fig. 2. The salivary digoxin concentration before and during continuous stimulation by chewing on cotton rolls of 22 salivettes during 37 minutes. The first 6 and and last 6 columns (salivary flow rate) represent unstimulated (b buccal and $s$ sublingual) saliva and the columns between represent flow rates stimulated by chewing. All samples were taken consecutively with a 20 minutes break between the $16^{\text {th }}$ and $17^{\text {th }}$ sample. The male, healthy proband (50 years) took $0.5 \mathrm{mg}$ digoxin at 15 days and the last dose 7 hours prior to sampling.

ar $\mathrm{K}^{+}$,

$\square--\square \quad \mathrm{Na}^{+}$,

$x \rightarrow x \quad$ osmolality,

- salivary digoxin,

$\Delta \quad$ total digoxin in serum,

$\Delta$ free (unbound) digoxin in serum. 
tion. In stimulated saliva, however, the digoxin and sodium concentration behaved inversely. The potassium concentration showed less variation.

In further experiments, "plateau levels" were taken as the mean value from several plateau concentrations and used as the digoxin concentration in stimulated saliva.

In the next experiment the digoxin concentrations in stimulated $\left(c_{S S A}\right)$ and unstimulated $\left(c_{\mathrm{SA}}\right)$ saliva were compared with the total digoxin concentration in serum and erythrocytes, and with the protein-unbound concentration in sera from 7 probands (fig. 3). The saliva/serum concentration ratio of digoxin $\left(c_{\mathrm{sSA}} / c_{\mathrm{S}}\right)$ was 0.69 after a single dose. This value was close to the one reported by Mahmod et al. (9), and it decreased to 0.53 in the steady state. The digoxin concentration in the erythrocytes increased in the steady state above the total serum concentration. In consequence, the ratio $c_{\mathrm{E}} / c_{\mathrm{S}}$ rose from 0.72 to 1.21 . The digoxin concentration in unstimulated saliva was also higher than the serum level in the steady state.

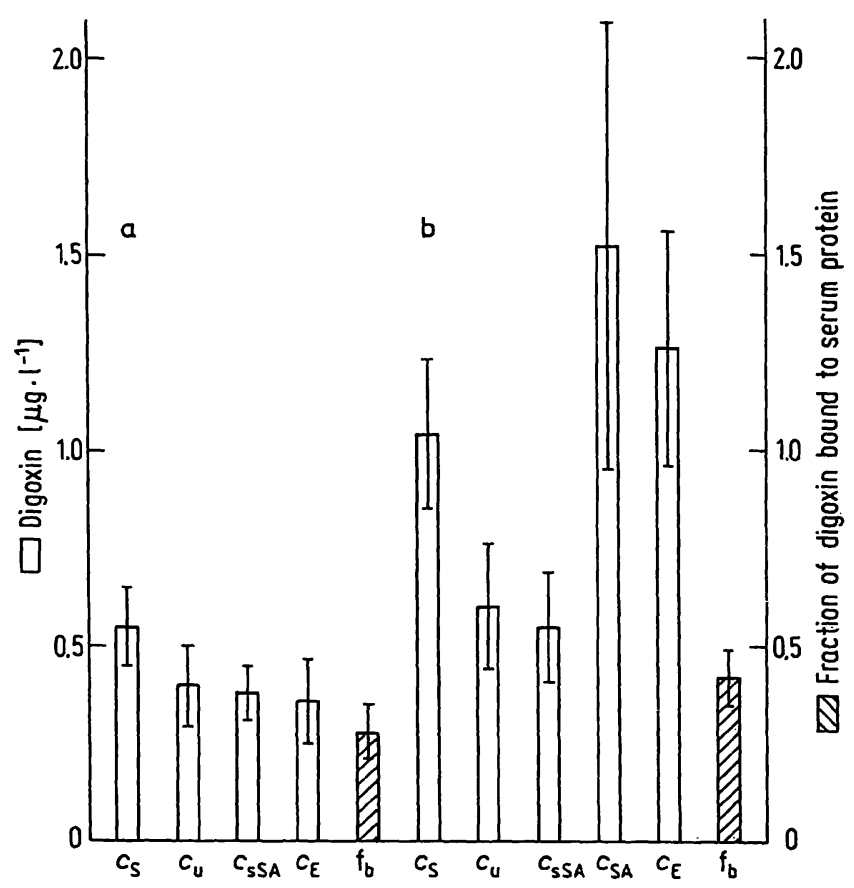

Fig. 3. The digoxin concentration in serum, erythrocytes and saliva

a) 12 hours after the intake of a single dose $(0.5 \mathrm{mg})$ and

b) 12 hours after the last intake of the drug in the steady state ( $0.5 \mathrm{mg}$ at 10 days).

Mean values of 6 male probands and one woman with standard deviations.

$c_{\mathrm{s}}=$ concentration in serum,

$c_{U}=$ free concentration in serum (ultrafiltrate),

$c_{\mathrm{sSA}}=$ concentration in stimulated saliva,

$c_{\mathrm{SA}}=$ concentration in unstimulated saliva,

$c_{\mathrm{E}}=$ concentration in erythrocytes,

$\mathrm{f}_{\mathrm{b}}=$ fraction of serum protein bound drug (total minus free divided by total concentration).
The digoxin concentrations in serum water (free fraction) and in stimulated saliva are similar in the presteady state as well as in the steady state. The serum fraction of bound digoxin also significantly rose from 0.28 to 0.42 (t-test, $\mathrm{p}<0.05$ ).

The experiment was repeated with 3 probands, using a higher first dose of $1.0 \mathrm{mg}$ digoxin to exclude any influence of the total serum concentration on the observed ratios. The mean ratio $c_{\mathrm{E}} / c_{\mathrm{S}}$ was again 0.69 in the pre-steady state and 1.42 in the steady state, and the mean $c_{\mathrm{SA}} / c_{\mathrm{S}} 0.81$ and 1.43 , whereas the mean $c_{\mathrm{SSA}} / c_{\mathrm{S}}$ ratio decreased slightly from 0.63 to 0.57 (fig. 4).

If digoxin was applied for several days, the protein binding capacity of serum was significantly increased, and an even greater increase occurred in the intracellular binding and in the ratio of the unstimulated to stimulated saliva concentration of the drug.

\section{Discussion}

Digoxin is a non-ionised, neutral and relatively lipophilic substance. Therefore, it should easily diffuse from the blood compartment into saliva, independently of variations in the the $\mathrm{pH}$-gradient. Mahmod et al. (9) have pointed out that digoxin appears in saliva at its maximum level within 1 minute of intravenous injection. Joubert (12) has observed that contamination can occur and recommended that mixed saliva should be collected just prior to oral administration of the next digoxin dosage. With this precaution, the salivary digoxin concentration should reflect the free (non-protein bound) fraction of plasma or serum digoxin, as has been postulated for several drugs which freely diffuse from the blood into saliva.

In accordance with this hypothesis, the digoxin concentration in stimulated saliva was close to the free serum concentration. For other drugs Wood et al. (17) have also assumed that increased flow rate tends to restore the salivary concentration towards the free unbound plasma concentration of the drug.

Jusko (3) noticed that stimulation of the salivary flow rate by chewing on Parafilm plates reduces the variability of the saliva/plasma distribution ratio, but it also causes a slight reduction of the saliva concentration of digoxin, an observation confirmed by our present results.

Burgen (18) reported an inverse function of the secretion rate and the salivary concentration of methenamine and several other substances. He pointed out that penetration through the resting membrane occurs 


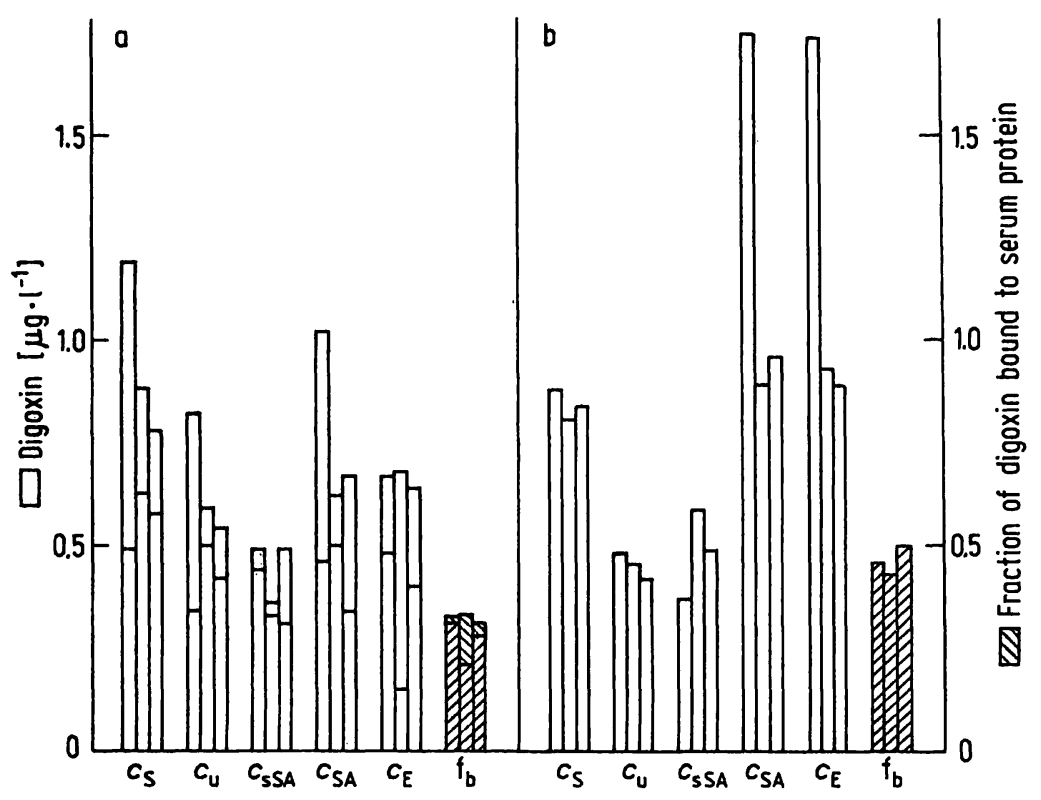

Fig. 4. The dioxin concentration in serum, erythrocytes and saliva

a) 12 hours after the intake of a single dose $(0.5 \mathrm{mg}$, lower part of the columns, and $1.0 \mathrm{mg}$, whole columns) and

b) 12 hours after the last intake of the drug in the steady state $(0.5 \mathrm{mg}$ at 10 days).

Column 1 is from a woman (48 years), column 2 and 3 are from male probands (50 and 26 years).

$c_{S}=$ concentration in serum,

$c_{U}=$ free concentration in serum (ultrafiltrate),

$c_{\mathrm{sSA}}=$ concentration in stimulated saliva,

$c_{\mathrm{SA}}=$ concentration in unstimulated saliva,

$c_{\mathrm{E}}=$ concentration in erythrocytes

$\mathrm{f}_{\mathrm{b}}=$ fraction of serum protein bound drug (total minus free divided by total concentration).

largely through the membrane lipid, but the increase in permeability e.g. with nerve stimulation is largely due to opening of water-filled pores in the membrane. If the decrease of the drug concentration could be explained by a simple dilution effect, then the osmolality should have shown a similar decrease.

In unstimulated saliva the digoxin concentration did not correlate with the total or with the free serum concentration, but with the concentration in the erythrocytes.

It is well known that digoxin is concentrated in muscle and other tissues including erythrocytes (14). The concentration in erythrocytes is often used as an easily accessible indicator for the concentration in muscle cells. The large volume of distribution $(3-10 \mathrm{l} / \mathrm{kg})$ is a further proof for the significant binding of digoxin to tissues $(14,19)$. Lazowski et al. (10) have also suggested an accumulation in salivary glands.

Therefore, it could be that unstimulated saliva reflects the intracellular digoxin concentration and stimulated saliva the free digoxin concentration in plasma.
Whether an active process accounts for the difference between unstimulated and stimulated saliva, as postulated for the kidney $(20,21)$, is not known. It is also unclear whether the total erythrocyte digoxin concentration represents that to which the digoxin receptors in body are exposed, as already assumed by Krivoy et al. (8).

In conclusion, salivary digoxin arises from 2 components: a diffusion component which approximates to the free digoxin level in serum, and a second component which exchanges slowly with the cellular compartment and may reflect the intracellular concentration. The latter concentration may parallel the pharmacologically relevant fraction, but this needs further clarification.

The saliva/serum ratio of the digoxin concentration varies with transition from a single dose to the steady state and with the increase of the salivary flow rate. Both effects have to be taken in account when interpreting the saliva/serum ratio and they may explain the conflicting results in the literature. 


\section{References}

1. Horning, M. G., Brown, L., Nowlin, J., Lertratanangkoon, K., Kellaway, P. \& Zion, T. E. (1977) Use of saliva in therapeutic drug monitoring. Clin. Chem. 23, 157-164.

2. Ritschel, W. A. \& Tompson, G. A. (1983) Monitoring of drug concentration in saliva: a non-invasive pharmacokinetic procedure. Meth. Find. Exptl. Clin. Pharmacol. 5, $511-525$.

3. Jusko, W. J., Gerbracht, L., Golden, L. H. \& Koup, J. R. (1975) Digoxin concentrations in serum and saliva. Res. Commun. Chem. Pathol. Pharmacol. 10, 189-192.

4. Huffman, D. H. (1975) Relationship between digoxin concentrations in serum and saliva. Clin. Pharmacol. Therap. $17,310-312$.

5. Jourbert, P. H., Muller, F. O. \& Aucamp, B. N. (1976) Salivary digoxin concentration in saliva and serum. Br. J. Clin. Pharmacol. 3, 673-674.

6. Van der Vijgh, W. J. F. (1975) Comparison of salivary digoxin concentration with plasma levels in man. Neth. $J$. Med. 18, 269-272.

7. Allonen, H., Jisalo, E., Kangan, L., Lammintausta, R. \& Salonen, M. (1978) Estimation of pharmacokinetic parameters of digoxin from serum, saliva and urine. Int. J. Clin. Pharmacol. 16, 420-423.

8. Krivoy, N., Rogin, N., Greif, Z., Ben-Aryeh, N., Gutman, D. \& Alroy, G. (1981) Relationship between digoxin concentration in serum and saliva in infants. J. Pediatr. 99, 810-811.

9. Mahmod, S., Smith, D. S. \& Landon, J. (1987) Radioimmunoassay of salivary digoxin by simple adapatation of a kit method for serum digoxin: saliva/serum ratio and correlation. Ther. Drug. Monit. 9, 91-96.

10. Lazowski, J., Lypka, A. \& Borkowski, P. (1978) The relationship between digoxin concentration in saliva and serum. Pol. Med. Weekly 33, 1709-1711.
11. Danhof, M. \& Breimer, D. D. (1978) Therapeutic drug monitoring in saliva. Clin. Pharmacokinet. 3, 39-57.

12. Joubert, P. H.; Muller, F. O. \& Aucamp, B. N. (1976) Digoxin concentration in serum and saliva: relationship to ECG changes and dosage in healthy volunteers. Brit. J. Clin. Pharmacol. 3, 1053-1056.

13. Haeckel, R. \& Bucklitsch, I. (1987) The comparability of ethanol concentrations in peripheral blood and saliva. $J$. Clin. Chem. Clin. Biochem. 25, 199-204.

14. Gorodischer, R. V., Jusko, W. J. \& Yaffe, S. J. (1975) Tissue and erythrocyte distribution of digoxin in infants. Clin. Pharm. Ther. 19, 256-263.

15. Vermeij, P. V. (1979) Monitoring of free plasma propranolol. Pharm. Weekbl. Sci. 1, 705-711.

16. Feldmann, U., Schneider, B., Klinkers, H. \& Haeckel, R. (1981) A multi-variate approach for the biometric comparison of analytical methods in clinical chemistry. $J$. Clin. Chem. Clin. Biochem. 19, $121=137$.

17. Wood, J. H., Flora, K. P., Narasimhachari, N. \& Baker, Ch. A. (1982) Dependence of salivary drug concentration on salivary flow rate. Meth. Find. Exptl. Clin. Pharmacol. $4,255-260$.

18. Burgen, A. S. V. (1956) The secretion of non-electrolytes in the parotid saliva. J. Cell. Physiol. 48, 113-138.

19. Soldin, St. J. (1986) Digoxin - Issues and controversies. Clin. Chem. 32, 5-12.

20. Steiness, E. (1974) Renal tubular secretion of digoxin. Circulation 50, 103-107.

21. Sumner, D. J. (1976) Digoxin pharmacokinetics: multicompartmental analysis and its clinical implications. Brit. J. Clin. Pharm. 3, $221=225$.

Prof. Dr. R. Haeckel

Institut für L̇aboratoriumsmedizin

Zentralkrankenhaus St. Jürgenstraße

D-2800 Bremen 1 